\title{
Porque nem toda feiticeira é corcunda: sentidos sobre o ser bruxa/ser mulher em filmes infantis e infantojuvenis
}

\section{Felipe Viero Kolinski Machado Mendonça}

Universidade Federal de Ouro Preto, Programa de Pós-Graduação em Comunicação, Mariana, MG, Brasil ORCID: https://orcid.org/0000-0002-8051-126X

\section{Jussara de Souza Lima da Silva}

Universidade Federal de Ouro Preto, Programa de Pós-Graduação em Comunicação, Mariana, MG, Brasil ORCID: https://orcid.org/0000-0003-2574-5239

\section{Resumo}

O objetivo deste trabalho é perceber como determinados filmes voltados ao público infantil e infantojuvenil representam a figura da bruxa/mulher. Para isso, empreendemos uma análise crítica cultural da mídia, tendo como base referenciais dos estudos de gênero/estudos feministas. Com Convenção das Bruxas, Abracadabra, Da magia à sedução e Harry Potter e a Pedra Filosofal, percebemos múltiplas representações. Por entre a figura que incorpora o mal, a que não segue determinada performance e merece ser punida, aquela que percebe a relevância da sororidade e aquela que encarna o gênero de um modo desejável temos, para além do enredo fantástico, uma discussão política sobre modos de ser/de não ser mulher.

\section{Palavras-chave}

Bruxa/Mulher. Gênero. Representação.

Filmes infantis/infantojuvenis. Análise crítica cultural da mídia. 


\section{Introdução}

Tomando como ponto de partida a representação da bruxa em determinadas produções cinematográficas (comerciais, hegemônicas, produzidas por grandes estúdios e com vastas bilheterias) voltadas ao público infantil e infantojuvenili1 ${ }^{1}$, quais sentidos, então, são materializados acerca do feminino?

Esse questionamento, o qual nos impulsiona no texto, inscreve-se em uma tradição de pesquisas que evidenciam uma relação historicamente estabelecida entre as figuras da bruxa e da mulher (MURARO, 2002; FEDERICI, 2017; ZORDAN, 2005; PORTELA, 2017; RUSSELL; ALEXANDER, 2019).

Ao tomarmos a cultura pop como lugar privilegiado para que se observem disputas simbólicas e materiais em torno da significação e, ainda, de questões ligadas às representações (SÁ; CARREIRO; FERRARAZ, 2015), empreendemos uma análise crítica cultural da mídia (KELLNER, 2001), ancorados em aportes teóricos e políticos caros aos estudos de gênero/estudos feministas (BEAUVOIR, 1967; LAURETIS, 1994; WITTIG, 2010; BUTLER, 2012; PRECIADO, 2014).

Neste trabalho, um movimento exploratório inscrito em um projeto mais amplo que visa a refletir acerca das representações de gênero na saga Harry Potter, selecionamos quatro filmes que se destacaram tanto por sinalizarem lugares plurais naquilo que tange às representações da bruxa/mulher quanto por, desde uma lógica afetiva/subjetiva (STEWART, 2007), terem nos impactado. Ao concebermos Convenção das Bruxas (1990), Abracadabra (1993), Da magia à sedução (1998) e Harry Potter e a Pedra Filosofal (2001) como tecnologias de gênero (LAURETIS, 1994) e, ainda, como dispositivos discursivos das feminilidades (MACHADO, 2018), perguntamos: quais sentidos, a partir dessas narrativas fílmicas, se estabelecem sobre o ser bruxa/ser mulher?

\section{Bruxaria e relações com o feminino}

Por entre a realidade e a ficção, diferentes discursos deram forma à imagem da bruxa e, também, à imagem da mulher. Tanto um discurso eclesiástico, o qual, durante séculos, constituiu-se em oposição às arcaicas práticas pagãs, quanto um romântico que, a

\footnotetext{
1 Indo ao encontro das reflexões desenvolvidas por João Batista Melo (2011), em obra oriunda de tese pioneira sobre o cinema infantil no Brasil, a classificação faria referência às obras destinadas ao segmento de público que se encontra na faixa etária conceituada como sendo a infância. Nesse mesmo sentido, os filmes infantojuvenis seriam aqueles que também abarcariam os adolescentes. Segundo o Estatuto da Criança e do Adolescente (ECA), a criança é todo o sujeito com até 12 anos incompletos, ao passo que o adolescente é o sujeito com idade entre 12 e 18 anos. Todos os filmes aqui estudados (com exceção de "Da magia à sedução", cuja classificação indicativa é 12 anos) possuem classificação indicativa livre.
} 
partir do século XIX, valorizou o que seria uma antiga religião que havia sido incompreendida, são índices de alguns dos lugares que o pensamento ocidental destinou, e ainda destina, ao feminino (RUSSELL; ALEXANDER, 2019).

Ainda que a imagem da bruxa possa soar diversa e ainda que as origens desses traços possam ser distintas, o que se estabelece, em muitos contextos (e em especial no imaginário advindo desse discurso eclesiástico), é a necessidade de, sob a lógica patriarcal (SAFFIOTI, 2015)2 ${ }^{2}$, controlar essa mulher perigosa, que se vale de um poder que misteriosamente possui e que escapa a uma máquina civilizatória que deve, para operar, mantê-la subjugada ao masculino (ZORDAN, 2005).

Indo ao encontro de Rose Muraro (2002), em introdução escrita para edição do Malleus Maleficarum (manual de reconhecimento e de perseguição aos praticantes de heresia ou, de modo mais específico, às praticantes de bruxaria), entre o fim do século XIV e meados do século XVIII é que teria acontecido, como fenômeno generalizado, uma repressão sistemática ao feminino: a caça às bruxas. Ainda que o número total de vítimas siga incerto, dados indicam que, em certas cidades, uma média de duas mulheres eram queimadas vivas por dia (MURARO, 2002).

Como sugere Paola Zordan (2005, p. 333), é possível perceber que, em sendo expurgo dos males atribuídos ao feminino, "a bruxa serviu como função pedagógica de cunho moralizador durante os séculos em que a Igreja focou a doutrina cristã no combate ao mal". Naquele cenário, uma vez que não se poderia, em sendo mulher, ter a capacidade de realizar fenômenos grandiosos, a bruxa obteria seus poderes a partir das relações inclusive sexuais - que estabeleceria com o diabo. Essas mulheres, as bruxas, seriam aquelas que poderiam, dentre outros malfeitos, desencadear a impotência masculina, gerar paixões desordenadas, arruinar colheitas e realizar abortos (PORTELA, 2017).

Nesse mesmo sentido, tal qual ressalta Silvia Federici (2017), a caça às bruxas, e sua matriz misógina, constitui, ainda, um dos acontecimentos mais importantes do desenvolvimento da sociedade capitalista, uma vez que teria aprofundado a divisão entre homens e mulheres, sancionado a submissão feminina e destruído um universo de práticas cuja existência era incompatível com tal sistema.

Ainda que tais representações tenham se consolidado em um imaginário coletivo e que ainda se façam fortemente presentes em distintos segmentos, é fundamental destacar

\footnotetext{
20 patriarcado, aqui, é concebido, a partir das reflexões de Heleieth Saffioti (2015), como um modo de dominação/exploração mais amplo o qual, em um contexto generificado, faz com que as mulheres sejam colocadas à margem, passando a ocupar uma posição de não-sujeito em relação aos homens.
} 
que outros sentidos sobre a bruxaria também puderam se materializar. 0 surgimento da bruxaria religiosa moderna, cujas raízes remontam ao movimento romântico, produz, também, um fenômeno de ressignificação que, igualmente, é perceptível contemporaneamente e que pouco tem a ver com seu homônimo medieval. Com a publicação de livros sobre a bruxaria moderna e com a expansão da Wicca (religião neopagã), o interesse pelo tema cresce exponencialmente. Outra importante difusão do conhecimento sobre a bruxaria e a bruxaria moderna, lembram Russell e Alexander (2019), é a sua relação com a cultura pop. Ainda que os autores mencionem Jovens Bruxas $\left(1996^{3}\right.$ apud RUSSEL; ALEXANDER, 2019), filme de 1996, como um marco naquilo que se refere à popularização da bruxaria moderna, a bruxa já era pop e já era uma representação constante em diversas produções (MOSELEY, 2002).

\section{Da cultura pop, da cultura da mídia e de nossa proposta de pesquisa}

Tal qual salientam Thiago Soares (2014) e Jeder Janotti Junior (2015), ao falarmos em cultura pop, estamos fazendo menção a um "popular midiático" e a um "popular massivo", ou seja, estamos nos referindo a produtos midiáticos voltados a um grande público e sob as premissas das indústrias da cultura. Nesse mesmo sentido, a cultura pop pode ser aqui compreendida como um termo aglutinador de um campo de tensões e de disputas simbólicas, o qual seria acionado por manifestações culturais populares/midiáticas advindas de múltiplos espaços. Ao mesmo tempo que a cultura pop diz de uma volatilidade de produtos culturais, os quais são atravessados por uma lógica mercadológica que é transitória, ela exerce "profunda influência no(s) modo(s) como as pessoas experimentam o mundo ao seu redor" (SÁ; CARREIRO; FERRARAZ, 2015, p. 9), desafiando fãs e também pesquisadores enquanto constelação afetiva contemporânea.

Douglas Kellner (2001) lembra que lutas concretas da sociedade são fortemente postas em cena em textos midiáticos que se voltam ao entretenimento. Ao salientar a importância de se examinar como essas produções transcodificam tais temáticas em seus diversos espetáculos, Kellner (2001, p. 13) sugere que a mídia seja compreendida como uma série de produções complexas, a qual incorpora discursos sociais e políticos e que, para além de um espaço de divertimento, é também um espaço de aprendizagem.

\footnotetext{
${ }^{3}$ JOVENS Bruxas. Direção: Andrew Fleming. EUA: Columbia Pictures. 1996. 1 DVD (101 min). Título original: The craft. Apud Russell e Alexander (2019).
} 
No escopo dessas reflexões, a questão que aqui nos mobiliza seria perceber, tendo em vista determinadas produções cinematográficas que trazem a figura da bruxa em um lugar de protagonismo, quais sentidos se constituem acerca do ser mulher. Selecionamos quatro filmes que, desde uma lógica subjetiva/afetiva (STEWART, 2007), sinalizassem uma pluralidade de representações sobre a bruxa/mulher. São filmes que, inscritos na nossa infância, nos impactaram/afetaram desde esse lugar. Desde a origem desta pesquisa, portanto, assumimos, como lugar político, e também epistemológico, uma mirada feminista e um lugar de acafãs (JENKINS, 2015). Para além desses aspectos subjetivos, ao passo que apresentarmos cada uma dessas produções, igualmente traremos justificativas que dizem de sua relevância/importância em um espectro mais amplo.

O que propomos aqui, então, é o desenvolvimento de uma análise crítica cultural da mídia (KELLNER, 2001) a qual, tendo como referenciais teórico-políticos os estudos de gênero/feministas, objetiva perceber os sentidos que se constituem, sobre a representação da bruxa/mulher, nessas produções cinematográficas. Tal análise, ensina Kellner (2001, p. 21), ao se basear em estudos midiáticos, em métodos de crítica cultural e em teorias modernas e pós-modernas que dizem das disputas políticas e ideológicas da sociedade, daria a ver "o modo como várias formas dessa cultura produzem prazer, opiniões e identidades que inibem ou fomentam as metas de maior democracia, igualdade e de uma sociedade realmente multicultural".

\section{Sobre gênero e (im)possibilidades de ser mulher}

Ainda que se apresente - e aí reside sua potência - como "expressão instintiva da verdade pré-discursiva da carne" (PRECIADO, 2014, p. 29), a identidade sexual consiste em uma fabricação, em um "um efeito de reinscrição das práticas de gêneros nos corpos" (PRECIADO, 2014, p. 29). A divisão masculino/feminino seria, então, uma categorização que dissimularia o fato de que as diferenças sociais implicariam uma ordem econômica, política e ideológica (WITTIG, 2010).

Longe de serem substâncias permanentes, portanto, sexo e gênero constituem-se a fim de garantir a manutenção de um sistema que é heteronormativo. Tomando o gênero como um contínuo fazer, como um devir e como uma atividade, Butler (2012) dirá que ele consiste em uma repetição que se dá no corpo, dentro de um quadro regulado e controlado, e que, ao longo do tempo, adquiriria a aparência de uma naturalidade. Mesmo que se conceba o caráter ficcional do sexo e do gênero, contudo, não é possível aviltar que, ainda 
que construções, tais categorias não sejam efetivas, não delimitem lugares permitidos e interditados aos corpos e que não sejam estruturantes de uma sociedade patriarcal (SAFFIOTI, 2015).

Ao ensinar que ninguém nasce mulher, mas sim se torna, Simone de Beauvoir (1967) empreende uma desnaturalização feminista do gênero. Beauvoir argumenta, ainda, que a mulher, em relação ao homem, sempre foi o outro, sempre teria sido o segundo sexo. 0 macho da espécie, nesse sentido, representaria aquilo que há de afirmativo, de assertivo, ao passo que à fêmea ficaria relegado o espaço da inessência.

A representação, como ensina Kathryn Woodward (2000), poder ser tomada como algo que, ao incluir as práticas de significação e os sistemas simbólicos por meio dos quais os significados são produzidos, torna-se fundante naquilo que se refere ao estabelecimento de identidades individuais e coletivas e para que, a partir de tal contexto, determinadas questões, sobre quem se é e quem se pode ser, possam ser respondidas.

Teresa de Lauretis (1994), ao abordar o modo como se dá a construção do gênero, recorre ao conceito de tecnologia de gênero. Para Lauretis (1994), várias tecnologias dentre as quais estaria inserido o cinema - poderiam produzir, promover e implantar representações de gênero. Rosa Maria Bueno Fischer (2002), ao discutir o que denomina como sendo o dispositivo pedagógico da mídia, salienta como a televisão, sendo partícipe do processo de constituição de subjetividades, age no sentido de ensinar aos seus públicos os modos de ser e de estar na cultura. Por seu turno, Fischer (2002) afirma que, na forma de aparatos discursivos e não discursivos, esse dispositivo incitaria continuamente um discurso sobre si mesmo e uma permanente revelação de si próprio.

Em pesquisa anterior (MACHADO, 2018, p. 118), quando se realizou uma investigação acerca de discursos mobilizados/construídos por revistas masculinas acerca de questões de gênero e de sexualidade, sugerimos que tais lugares fossem percebidos como dispositivos discursivos das masculinidades. Defendíamos, então, que tais publicações poderiam ser tomadas "como aparatos que, inseridos em determinada ordem discursiva, dariam a ver quais as possibilidades (e as impossibilidades) de se ser e de se estar no mundo como gay e como homem heterossexual". Aqui, voltando-nos a diferentes produções cinematográficas que, ao acionarem imagens de bruxas, dizem também sobre o feminino, acreditamos ser possível realizar movimento semelhante. Também na condição de dispositivos discursivos - agora das feminilidades - o que é possível, tendo em vista os sentidos que são constituídos nessas produções audiovisuais, apreender sobre o ser mulher? 


\section{Convenção das Bruxas e a (asquerosa) mulher (literalmente) fatal}

\section{Procurem essa titiquinha. Encontrem. Deve ser exterminada imediatamente.}

Convenção das Bruxas (1990).

Dirigido por Nicolas Roeg, Convenção das Bruxas (1990) consiste em uma adaptação cinematográfica de As Bruxas, romance de autoria de Roald Dahl (2019). A trama, uma comédia de terror, dá-se em um contexto no qual bruxas malvadas, que detestam crianças, tramam um plano para transformá-las em ratos. Um menino e sua avó, que estão no hotel onde ocorre a convenção anual das bruxas, precisam interromper esse projeto maligno. A protagonista, Senhorita Eva Ernst, a Grande Rainha Bruxa, na qual nos concentraremos aqui, é interpretada pela atriz Anjelica Huston (então com 40 anos). Ainda que tenha tido uma arrecadação mundial não tão elevada para os padrões da indústria (cerca de 15 milhões de dólares, conforme THE WITCHES, 2021), houve uma boa avaliação junto aos críticos e ao público, a atuação de Huston foi particularmente elogiada e o filme tornou-se celebrado (THE WITCHES, 2020).

Na narrativa audiovisual, as bruxas são descritas, a partir de apresentação que a avó faz ao neto, como mulheres, as quais seriam aparentemente normais mas que, na realidade, esconderiam sua verdadeira natureza. Ainda que com roupas comuns, as bruxas seriam criaturas monstruosas.

\footnotetext{
Bruxas de verdade odeiam crianças. Bruxas de verdade são meio carecas. Mas é claro que elas usam perucas, que coçam e causam feridas na cabeça [...] Elas são horríveis atrás das máscaras humanas. Você só pode distinguilas de mulheres comuns se for esperto o suficiente para perceber a coloração violeta dos olhos delas. As bruxas de verdade não têm os dedos dos pés, seus pés são quadrados [...] por isso elas nunca usam sapatos de bico ou bonitos. Só sapatos simples. Lembre-se disso! (CONVENÇÃO DAS BRUXAS, 1990).
}

Anne-Marie Bird (1998, p. 122), ao abordar a Grande Rainha Bruxa, ressalta como há um movimento em direção a uma sexualização da personagem (e a uma representação negativa também desse aspecto).“Ela é má/monstruosa [...] antes mesmo de tirar a máscara; uma femme fatale, ela é uma vampira predadora de salto alto, vestido preto justo e decotado, cabelos pretos severos e batom vermelho ardente, sedutora e assustadora enquanto olha 
para a câmera" (tradução livre4). Para além do mal que se expressa via performance erótica, Eva, "a mulher mais diabólica que existe", que almeja acabar com todas as crianças, é monstruosa, também, por aquilo que esconde por trás da máscara. Reunida com as demais bruxas, ela revela quem é de verdade: uma criatura (feminina) asquerosa, com nariz e orelhas enormes, face disforme, cabeça calva e pele escamosa/enrugada.

Convenção das Bruxas (1990), tal qual evidenciado por Bird (1998), recupera uma representação misógina daquilo que se compreenderia como uma bruxa. Ainda que produzido em finais do século $\mathrm{XX}$, o filme inscreve-se em um discurso eclesiástico, de demonização da figura feminina/da figura da bruxa, que marcou uma obra produzida cerca de cinco séculos atrás: o Malleus Maleficarum (KRAMER; SPRENGER, 2002). Tal qual pondera Portela (2017), teria sido a naturalização das identidades de gênero pela religiosidade dominante que, em um cenário europeu e medieval, viablizara a produção de instrumentos de autoridade masculina e de controle feminino. A caça às bruxas, então, representaria uma caça à mulher e uma garantia de domínio sobre ela, seu corpo e, claro, sua sexualidade.

Figura 1 - Grande Rainha Bruxa

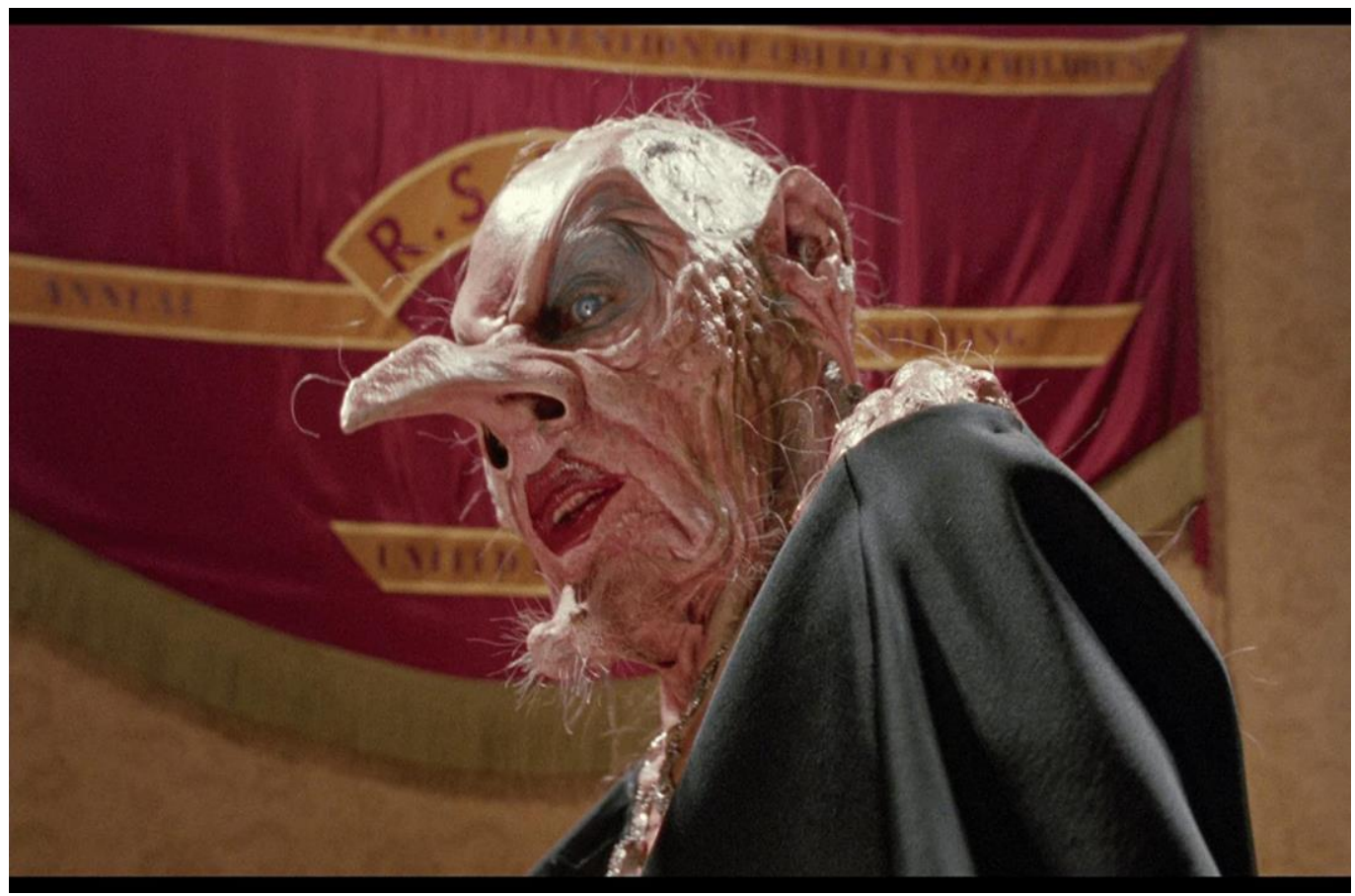

Fonte: Convenção das Bruxas (1990).

\footnotetext{
4 "She is evil/monstrous [...] before she even removes her mask; a femme fatale, she is a predatory vamp in her stiletto heels, tight, low-cut black dress, severe black hair, and blazing red lipstick, both alluring and frightening as she leers into the camera".
} 
No filme ora em tela, da mesma maneira, a bruxa/mulher é uma figura asquerosa, que perturba, que incomoda mas que, de algum modo, também fascina. A mulher que performa o feminino desse modo irregular e a bruxa que encarna o mal são corpos fundamentalmente estranhos (LOURO, 2008). Ardilosa, Eva Ernst, assim como sua antepassada de mesmo nome, é responsável pelo mal, pelo descontrole, pelo pecado. Bird (1998, p. 125) pondera que "no filme, a figura da bruxa (fascinante e repulsiva ao mesmo tempo) provoca uma perturbação ou confronto com as fronteiras entre o humano e o não humano" (tradução livre ${ }^{5}$ ). Nesse mesmo sentido, ao mesmo tempo que a "máscara humana" esconde um ser abjeto, essa mesma máscara cria uma relação com outro corpo que, sob uma visada misógina e patriarcal, também é asqueroso: a mulher Eva Ernst. Corpos distintos mas que, igualmente perigosos, precisam ser controlados. Eva é vítima de seu próprio veneno/poção. Ao tomar inadvertidamente uma sopa que contém a substância capaz de transformar crianças em ratos, ela se transforma num roedor, é aprisionada pela avó do garoto e esquartejada com um cutelo pelo gerente do hotel. Bruxa/Mulher (nesse momento também rata) que é, portanto, aniquilada.

\title{
6 Abracadabra e a hipérbole da mulher/bruxa em busca da juventude eterna
}

\author{
- Irmãs, vejam! Somos jovens! \\ - E bonitas! Os rapazes me amarão! \\ - Somos jovens! \\ - Bem, mais jovens! Mas já é o começo! \\ - Mana, tu és apenas uma mera menininha! \\ - Tu mentes! Mas eu serei uma menina para sempre depois que eu \\ sugar a força vital de todas as crianças de Salem! \\ Abracadabra (1993).
}

Abracadabra (1993) consiste em um filme de comédia/fantasia produzido pela Walt Disney Pictures. Sob a direção de Kenny Ortega, o filme trouxe como vilãs/protagonistas as atrizes Bette Midler (48 anos à época), Kathy Najimy (36 anos à época) e Sarah Jessica Parker (28 anos à época), arrecadou cerca de 40 milhões de dólares e se configurou num clássico do gênero (CHANEY, 2015).

No contexto da trama, na cidade estado-unidense de Salem, no ano de 1693, depois de atraírem uma menina até sua casa, na floresta, e, a partir de uma poção, terem extraído

\footnotetext{
5 "The figure of the witch (both fascinating and repulsive at the same time) brings about a disturbance of, or confrontation with, the boundaries between the human and the nonhuman".
} 
sua força vital para se tornarem mais jovens (e mais belas), as irmãs Sanderson (Winifred, Mary e Sarah) são condenadas à morte por bruxaria. Prestes a serem enforcadas, as bruxas lançam uma maldição e garantem o seu retorno ao mundo dos vivos quando um virgem, na noite de todos os santos, acendesse a vela da chama negra. Passados três séculos, em 1993, a maldição é cumprida e, por uma noite, as bruxas retornam. Contudo, para permanecerem vivas e (tão relevante quanto) manterem-se jovens, elas precisam se alimentar.

Assim como ocorre em Convenção das Bruxas (1990), a narrativa de Abracadabra (1993) filia-se ao discurso eclesiástico e misógino de demonização do feminino/bruxaria e, inclusive inscrevendo-se historicamente, retrata a caça às bruxas perpetrada no século XVII, no estado de Massachusetts. Maléficas e perigosas, as bruxas/mulheres de Abracadabra, tal qual as bruxas/mulheres não ficcionais de Salem, encontram na execução a solução que o patriarcado concebe para a sua existência indesejável.

Mulheres incômodas para a comunidade, viúvas solitárias ou vizinhas indiscretas, as bruxas eram aquelas cujas práticas eram consideradas crimes mais graves do que as heresias. Sedenta por poder, a bruxa é maléfica e corruptora, de modo que, tanto na realidade como na ficção, todas as histórias de bruxas terminam com o castigo por sua insubmissão: forca, fogueira, solidão. (ZORDAN, 2005, p. 333).

Figura 2 - Irmãs Sanderson

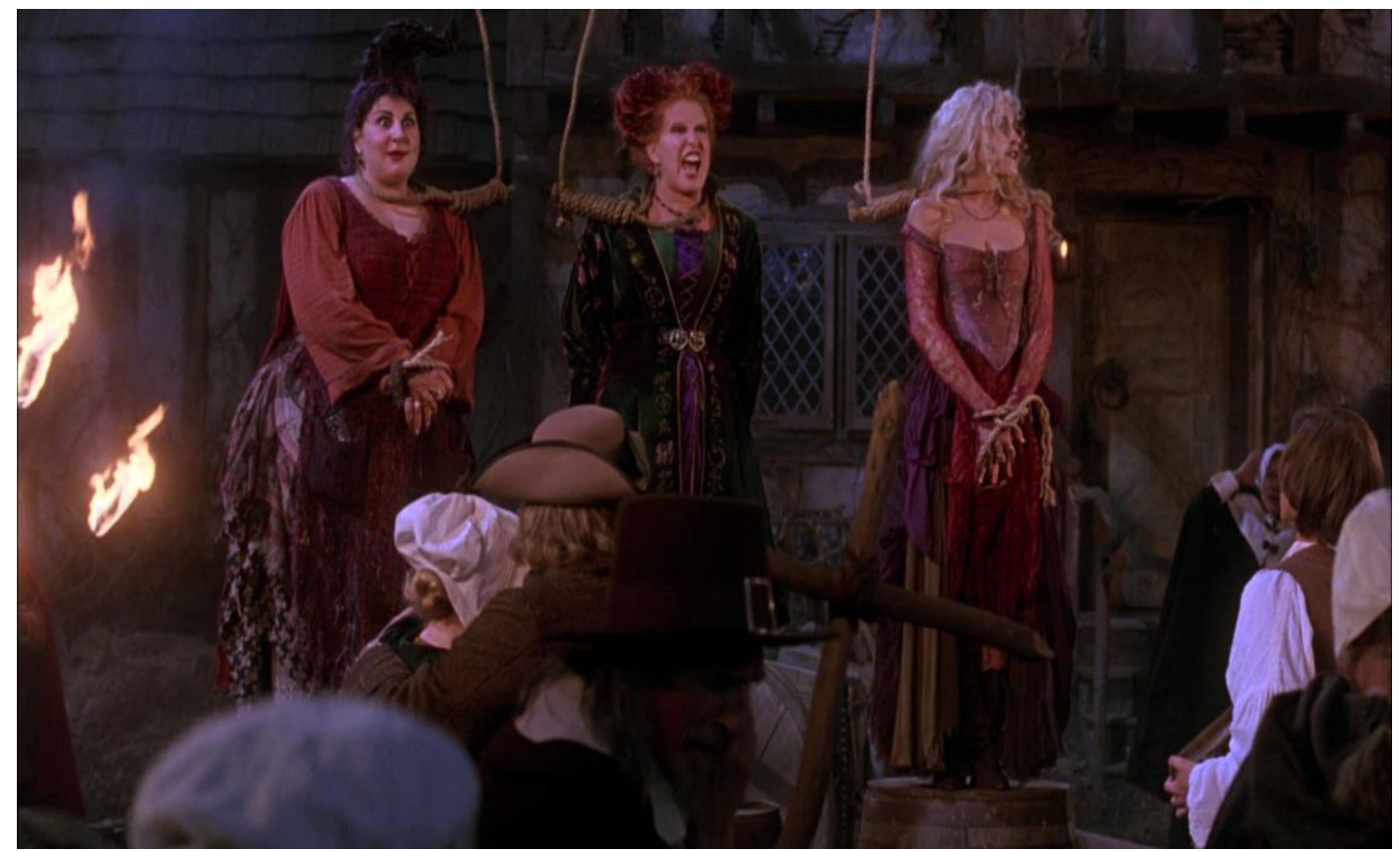

Fonte: Abracadabra (1993). 
Cabe ressaltar, ainda, naquilo que tange às performances das três personagens, a recorrência de alguns lugares comuns (tanto em relação às bruxas, que devem ser assassinadas, quanto em relação a algumas mulheres, que devem ser punidas). Winifred, a irmã mais velha e a líder, é a mais esperta, malvada e ardilosa. Mary, a irmã do meio, não por acaso uma personagem gorda, assume em diversos momentos aspectos selvagens/animalescos: ela, como um cão, tem um ótimo olfato, utilizando-o na busca de crianças e, também como um cão, late/gane ao se sentir acuada. Sarah, a mais jovem, é extremamente sensual e, ao longo do filme, flerta com diversos homens. Todas essas características (maldade, selvageria e sensualidade exacerbada) eram recorrentemente retomadas nos movimentos de condenação por bruxaria (RUSSELL; ALEXANDER, 2019). As três irmãs, assim como Eva, de Convenção das Bruxas (1990), performam uma feminilidade asseverada pelo exagero: a maquiagem carregada, os gritos e as gargalhadas e os gestos largos não aparecem por acaso. Para além do caráter cômico da produção cinematográfica, e mais explicitamente quando, em uma festa, realizam um número musical, Winifred, Mary e Sarah, corpos também estranhos, executam uma paródia de gênero (BUTLER, 2012).

Em alguma medida canibais, as irmãs Sanderson da Disney também atualizam mitos ligados à história da bruxaria - e a sua perseguição - a partir desse lugar. A relação entre a figura da bruxa e o canibalismo é contínua e se manifesta de modo recorrente em uma multiplicidade de textos. Documentos históricos acerca da caça às bruxas perpetradas na Alemanha do século XVI, por exemplo, destacavam rituais em que as bruxas desenterravam cadáveres de crianças mortas de cemitérios para cozinhar e comer. 0 canibalismo também é uma característica da velha e má bruxa de João e Maria , texto clássico escrito pelos irmãos Grimm (20126 apud COSTA, 2020). Revisitada também em Abracadabra (1993) é a relação intrínseca entre bruxaria/velhice/feiura e a necessidade premente, por parte da bruxa/mulher, de se tornar mais jovem e, por conseguinte, mais bela. Essa, aliás, no escopo da narrativa, é a razão fundamental da busca por crianças, bem como do desejo de sugar suas vidas. A beleza, uma virtude que não pertence a essa criatura do mal, precisa, pois, ser conquistada, custe o que custar. Indo ao encontro das proposições de Naomi Wolf (1992, p 15), é possível constatar o seguinte: incorporar determinado tipo de beleza (condizente com o padrão estético hegemônico) converte-se numa obrigação feminina. Ainda que beleza não seja um significante universal, ele se reveste como se fosse. Atendê-lo torna-se fundamental para que tanto bruxa quanto mulher possam viver e sobreviver em uma lógica de

6 GRIMM, Irmãos. Contos maravilhosos infantis e domésticos. Christine Röhrig (Trad.). São Paulo: Cosac Naify. 2012. Tomos 1 e 2 . 
dominação masculina. Ao passo que a velhice, historicamente, passa a ser tomada com sinônimo de feiura, de incapacidade e de inaptidão, a juventude converte-se em desejo, em sonho. Antes relativa a determinado estágio do desenvolvimento biológico, a juventude, sob essa lógica, deixa de se configurar como um aspecto concernente à ordem cronológica e passa a se constituir em um valor que os sujeitos, e em especial as mulheres, devem obter (MACHADO, 2020). No filme ora em tela, cabe às irmãs se alimentarem de crianças para seguirem vivas e jovens para sempre. Para além da ficção, aprende-se que, na corrida pela beleza, tudo vale.

A punição para essa bruxa/mulher que escapa às normas, contudo, é evidente: ao longo de Abracadabra (1993), Winifred, Mary e Sarah são enforcadas, queimadas e, finalmente, explodidas.

\section{Da Magia à Sedução e a promoção da sororidade entre bruxas e mulheres}

Por mais de 200 anos, nós, as mulheres Owens, levamos a culpa por tudo o que dá de errado nesta cidade. Da Magia à Sedução (1998).

Dirigido por Griffin Dunne, Da Magia à Sedução (EUA, 1998, 93 min) é uma adaptação do livro de Alice Hoffman, Practical Magic. Ainda que pouco aclamado pela crítica especializada e ainda que tenha gerado uma arrecadação inferior ao seu custo de produção (custou cerca de 75 milhões de dólares e angariou cerca de 70), o filme, no espectro da representação da bruxa/mulher, é celebrado pela discussão potente que promove sobre resiliência e sororidade (BENNETT, 2018).

No contexto da trama, desde uma maldição lançada por uma ancestral, Maria, há 200 anos, os homens com quem as bruxas/mulheres da família Owens se relacionam amorosamente morrem de modo abrupto. Órfãs (o pai morreu em decorrência da maldição e a mãe morreu de tristeza), Sally (Sandra Bullock, à época com 33 anos) e Gillian (Nicole Kidman, à época com 30 anos) crescem sob os cuidados (e também ensinamentos) das tias. Ainda que tente escapar do amor, Sally acaba se casando, tendo duas filhas e, em seguida, torna-se viúva. Gillian, em contrapartida, relaciona-se com diversos homens sem que, necessariamente, apaixone-se por eles. Ainda que muito diferentes, as irmãs firmam um pacto por meio do qual ressaltam sua união e cuidados uma para com a outra. Anos mais tarde, ao sentir que Gillian corre perigo, Sally a salva de um relacionamento física e psicologicamente abusivo. Nesse resgate, Jimmy, o agressor, acaba sendo assassinado, 
ressuscitado e convertido em um espírito maligno que deseja vingança. Para se livrarem do espírito - que então coloca a vida de Gillian em risco - Sally, suas filhas e suas tias contam com o apoio das mulheres da cidade que, até pouco tempo, as desprezavam pelos boatos (fundados) de bruxaria.

Da Magia à Sedução (1998), em uma representação que se afasta daquela constituída em Convenção das Bruxas (1990) e em Abracadabra (1993), traz uma mulher/bruxa que se constrói a partir de um discurso romântico e não eclesiástico (RUSSELL; ALEXANDER, 2019). Afastando-se de figuras como Eva Ernst e as irmãs Sanderson, as bruxas/mulheres da família Owens são bondosas, generosas e, mesmo sedutoras, não são perversas. Ainda que Maria (condenada à morte por bruxaria também em razão de seus múltiplos amantes) e Gillian (vários namorados sucessivos) sejam "devassas" (em um significante que é evocado pela própria Gillian), tal característica é exposta como sendo algo que, mesmo condenado socialmente - e em especial por outras mulheres - não consistiria em um traço que afetaria o bom caráter dessas personagens. Ao passo que a eroticidade exacerbada da Grande Rainha Bruxa e de Sarah Sanderson era um motivo a mais (ou até mesmo um motivo central) para que aquelas mulheres/bruxas fossem lidas como vilãs e, por conseguinte, merecedoras de uma punição severa, o mesmo não se dá em Da Magia à Sedução (1998). Embora Sally desde o seu vestuário, constituído por peças mais delicadas e em tons claros, passando pelo fato de ter vivido um amor romântico e, ainda, ter tido filhas - performe um padrão hegemônico de feminilidade (BUTLER, 2012) e que Gillian - cabelos ruivos, maquiagem mais visível, roupas mais escuras/sensuais, múltiplos relacionamentos - seja a irmã que precisa ser salva, não se constitui, no escopo da trama, uma relação de combate ou de disputa entre as irmãs mas, ao invés disso, de amor e de cumplicidade.

Em um contexto patriarcal, a partir do qual se estimula/se promove a rivalidade e a competição entre mulheres (SAFFIOTI, 2015), apoiar-se e se perceber a partir dessa mesma marca identitária é um ato político e subversivo necessário. 0 termo sororidade, aqui evocado, diz do apoio incondicional entre mulheres como lugar importante para o enfrentamento da opressão de gênero. Para além de laços sanguíneos (os quais também podem estar envolvidos) descreve-se uma relação que é marcada pela solidariedade (MACIEL, 2019). Indo ao encontro das proposições de Marcela Lagarde (20127 apud BECKER; BARBOSA, 2016), é possível compreender sororidade como uma experiência subjetiva entre mulheres que, a partir de um apoio mútuo, visa a combater diferentes

7 LAGARDE Y DE LOS RÍOS, Marcela. El Feminismo en mi vida: hitos, claves, y topías. 2012. Disponível em: www.inmujeres.df.gob.mx. Acesso em: 20 out. 2016. Apud Becker e Barbosa (2016). 
formas de exploração. Lagarde destaca, ainda, que sororidade consistiria, também, em uma consciência crítica sobre a misoginia e em um esforço pessoal e coletivo a fim de descontruir tais lógicas que, em muitas situações, seriam replicadas pelas próprias mulheres.

Em Da Magia à Sedução (1998), tal qual mencionado, Gillian é vítima de um relacionamento marcado pela violência física e simbólica. Dados presentes em relatório divulgado pela ONU (UN WOMEN 2019), em 2019, indicaram que cerca de $20 \%$ das mulheres do mundo (com idade entre 15 e 49 anos) vivenciaram a mesma situação da personagem e, ainda, que 137 mulheres são assassinadas por um familiar do sexo masculino diariamente.

No Brasil, de modo mais específico, dados sinalizam (BRASIL, 2020) que, em média, três mulheres são vítimas de feminicídio por dia, sendo que em $80 \%$ das vezes o assassino é o companheiro ou ex-companheiro. Ainda que avessas às mulheres/bruxas da família Owens, ao receberem uma ligação com um pedido de ajuda, as mulheres da comunidade unem-se por um objetivo comum: salvar a vida de uma outra mulher que corre perigo. Mesmo diferentes (bruxas/não bruxas) todas são mulheres e, em uma cena emblemática, unidas em círculo, com suas vassouras (um ícone da bruxaria), ao salvarem alguém que seria mais uma vítima, dizem de uma força que reside no reconhecimento dessa semelhança.

Figura 3 - Ajuda à Gillian

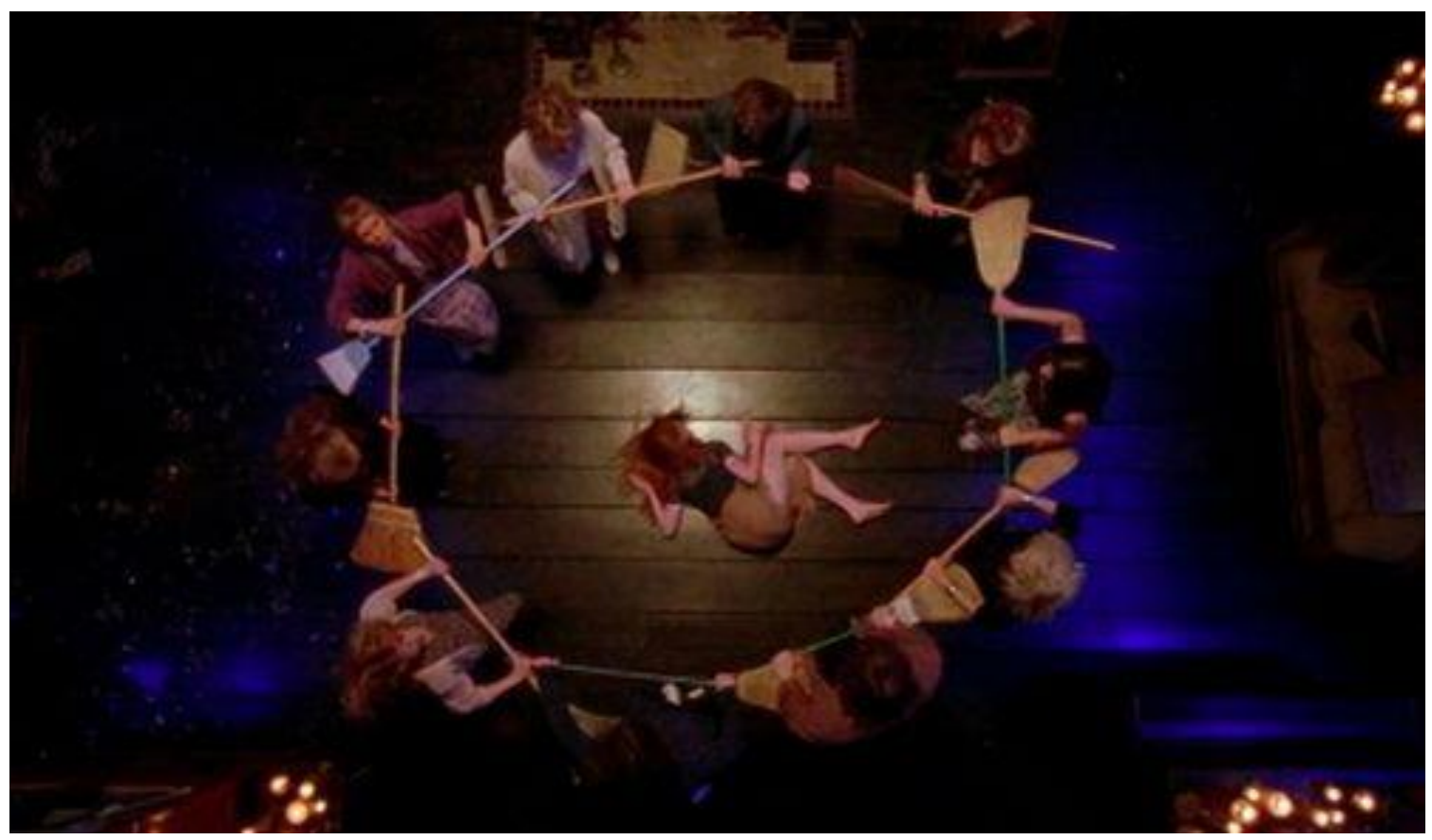

Fonte: Da Magia à Sedução (1998). 
Inscrevendo a imagem da mulher/bruxa em outra rede de sentidos, Da Magia à Sedução (1998) - com Sally, com Gillian, com as tias e com as mulheres não bruxas da cidade - ensina que, apesar das diferenças, há laços que são poderosos: laços de sangue, os quais são reforçados por meio de um pacto, mas, para além deles, laços que se estabelecem por meio de semelhanças que sobrepujam diferenças. Bruxas ou não bruxas, mulheres.

\title{
8 Harry Potter e a Pedra Filosofal e a representação da bruxa/garota ideal
}

\author{
- Wingardium Leviosa! \\ -Para. Para. Para. Assim você vai acabar arrancando o olho de \\ alguém. E você está falando errado. É leviOsa. E não levioSA. \\ -Faz você então se é tão esperta. Faz vai lá. \\ -Wingardium Leviosa! \\ -Ah! Muito bem! Estão vendo meninos? A senhorita Granger \\ conseguiu. \\ Harry Potter e a Pedra Filosofal (2001).
}

Harry Potter e a Pedra Filosofal (2001) foi a primeira adaptação cinematográfica de um dos livros da saga Harry Potter, escrita pela britânica Joanne Rowling. Com uma arrecadação da ordem de cerca de um bilhão de dólares, o filme, ao ser lançado, tornou-se a segunda maior bilheteria do cinema mundial (POTTER, 2002) e introduziu nos cinemas as aventuras do jovem bruxo. Dirigido por Chris Columbus, o filme narra o primeiro ano escolar de Harry Potter, o qual descobre que é um bruxo e ter direito a uma vaga na Escola de Magia e Bruxaria de Hogwarts. É lá que ele se torna colega e amigo de Hermione Granger (Emma Watson, 11 anos à época), principal personagem feminina da narrativa.

Antes de passarmos às discussões sobre a representação da bruxa/mulher a partir de Hermione, contudo, algumas questões merecem destaque. Na saga $H P$, o mundo mágico é uma realidade com a qual se convive (ainda que poucos saibam de sua existência). Paralelo a uma sociedade não mágica (chamada trouxa), existe toda uma sociedade mágica, com instituições formais, legislação e sistema monetário específicos. 0 caráter do indivíduo, tal qual ensina a história, não está ligado ao fato dele ser ou não um bruxo, uma vez que, tal qual entre trouxas, há feiticeiros de boa e de má índole. Igualmente, há que se ressaltar: ao contrário das outras personagens que aqui estudamos, em Hermione temos a representação de uma bruxa/mulher criança, o que mobiliza sentidos específicos.

Muito dedicada e muito inteligente, Hermione é apresentada, desde o início da trama, como alguém que detém grande conhecimento sobre esse universo então exposto à audiência. "Não é de verdade esse teto. Só foi enfeitiçado para parecer o céu à noite. Eu li 
sobre isso em Hogwarts: uma história" (HARRY ...2001). Da mesma maneira, ainda em sua primeira aparição, pela relação que se estabelece em especial com os garotos, somos introduzidos a uma Hermione que também tende a ser convencida e irritante.

- Alguém viu um sapo? Um garoto chamado Neville perdeu o dele.

- Não!

- Você está fazendo mágicas? Essa eu quero ver.

- Sol, margaridas, amarelo maduro, torna amarelo esse rato burro.

- Você tem certeza de que isso é mesmo um feitiço? Parece que não é muito bom, né? É claro que eu só tentei fazer alguns simples sozinha e não tive problemas. Por exemplo: oculus reparo. (HARRY POTTER..., 2001).

Guacira Lopes Louro (1997), ao abordar as relações entre gênero, sexualidade e educação, ensina que a escola consiste em um espaço generificado, ou seja: ao passo que também forja os gêneros, acaba sendo forjada por eles. Ao observarmos mais atentamente as escolas, é possível constatar como, por meio de regimentos e da organização do espaço e do tempo sob uma lógica binária, ensina-se também sobre como ser menino e sobre como ser menina (AUAD, 2006). Ao passo que os meninos são constituídos como potencialmente rebeldes e bagunceiros, as meninas precisam assumir uma performance que passa pelos lugares da dedicação e do autocontrole. "- Agora, se vocês dois não se importarem, vou para a cama antes que algum de vocês venha com alguma outra ideia inteligente que nos faça ser mortos, ou pior, expulsos! - Ela precisa rever suas prioridades" (HARRY...2001).

Ainda que Harry Potter e a Pedra Filosofal (2001) não seja uma produção nacional, ao ser veiculada em nosso país e, neste trabalho, ao ser investigada por pesquisadores brasileiros, consideramos ser potente pensar também a relação gênero/escola a partir de alguns dados específicos de nosso contexto. Um interessante levantamento sobre trajetórias estudantis de meninos e de meninas apontou que, embora meninos estudem, em média, por semana, uma hora a menos do que as meninas e 6 em cada 10 alunos que não atingiram o nível básico de proficiência em português, matemática e ciências fossem meninos, quatro vezes mais meninos que meninas intencionam seguir carreiras em setores como engenharia e informática (LOPES; SILVA, 2018). Ainda que esses dados sejam impactantes, torna-se fundamental ressaltar que tais aspectos dizem de construções culturais e políticas e de disputas ideológicas em torno daquilo que se toma como "masculino" e "feminino" e não de algo que seja "natural" ou "biológico". Indo ao encontro de Butler (2012), e ao compreender o gênero como performativo, torna-se flagrante que, no escopo da narrativa de Harry Potter e a Pedra Filosofal, Hermione performa um padrão hegemônico de feminilidade. Em uma Hogwarts atravessada tanto por magia quanto por questões de gênero, a menina/bruxa 
assume o lugar de dedicação, de comprometimento, de responsabilidade e de cumprimento das regras que, também no mundo trouxa, se espera das mulheres.

Figura 4 - Hermione

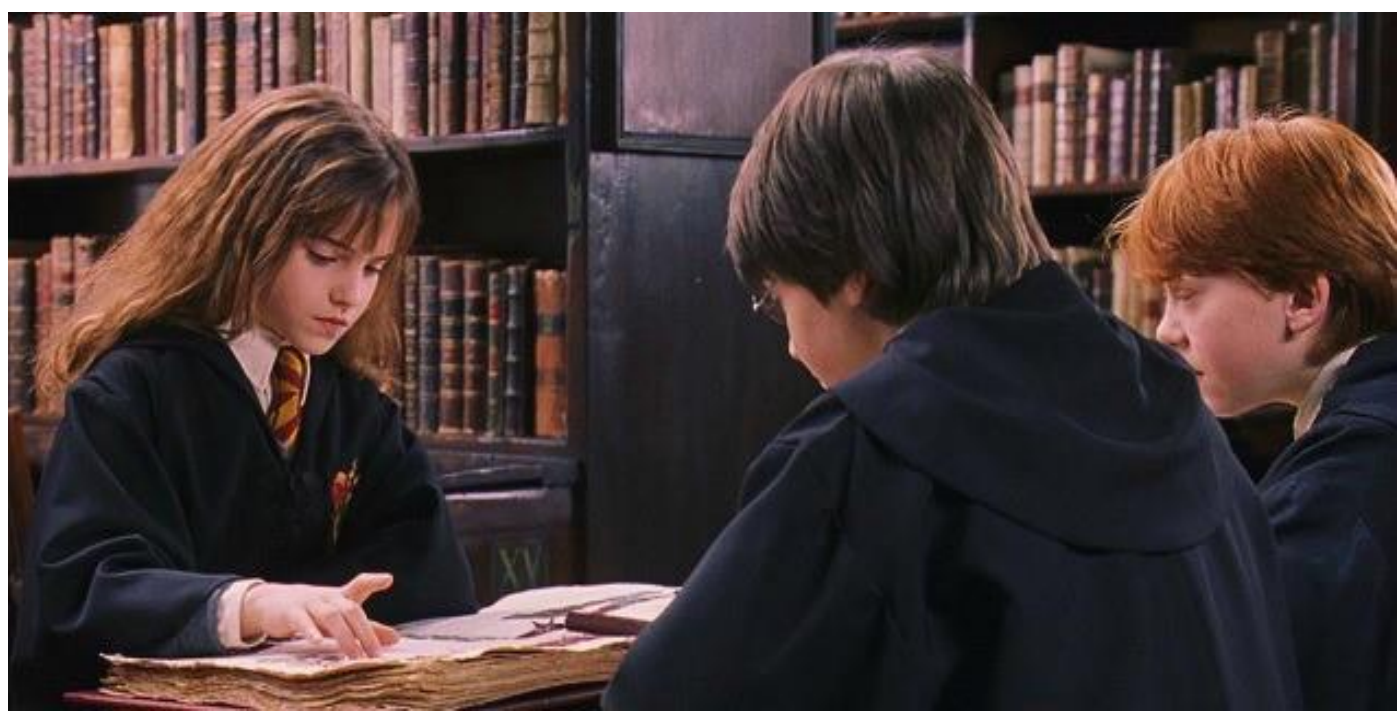

Fonte: Harry Potter e a Pedra Filosofal (2001).

Muito embora Hermione, em diversos momentos, tenha salvado a todos, no escopo da narrativa, tais ações tendem a ser minimizadas frente à coragem de Harry Potter. "- Você vai ficar bem Harry. Você é um grande bruxo, realmente é. - Não sou tão bom quanto você. Eu? Livros e inteligência. Há coisas mais importantes".

Hermione, menina/bruxa, mesmo ao demonstrar capacidade intelectual superior a dos colegas homens, tende a combinar qualidades esperadas de uma garota. Ainda que muito habilidosa e corajosa, seus feitos tendem a ser coadjuvantes, tal qual sua participação. Fazendo eco às reflexões de Beauvoir (1967), ensina-se, também, que a mulher tende a ser sempre o segundo, existindo em relação ao padrão que é masculino.

\section{Considerações finais}

Perturbadora e fascinante, inscrita na cultura a partir de lógicas misóginas e patriarcais (SAFFIOTI, 2015) que percebiam no maléfico poder feminino um perigo que precisava ser combatido ou, ao invés disso, como alguém que era detentora de grande conhecimento e que, em uma sociedade obscura, não foi compreendida, a bruxa é plural. Lida como a senhora dos descontroles, assinalada pela estridente gargalhada, que "guarda, sob os panos, truques que servem para confundir, embaçar e atrapalhar a razão" (ZORDAN, 
2005, p. 338), a bruxa/mulher também pode ser tomada como figura que diz de uma postura combativa em um mundo cujo gênero é o masculino (FEDERICI, 2004).

Compondo legiões no século XXI (afinal, a bruxa/mulher, para além da magia, seria aquela que questionaria um lugar de submissão que lhe fora imposto), e, não podendo mais ser queimada nas fogueiras das inquisições, a bruxa também seria responsável pela "reinserção do feminino na história, resgatando o prazer, a solidariedade, a não-competição e a união com a natureza" (MURARO, 2002, p. 17).

Tal qual destacado, a pesquisa aqui relatada consiste em um movimento ainda exploratório que visa a refletir acerca da representação da bruxa/mulher em produções cinematográficas hegemônicas voltadas ao público infantil e infantojuvenil. Indo ao encontro das proposições de Kellner (2001) acerca da cultura da mídia e, ao percebermos a bruxa como uma figura potente presente na cultura pop - que diz também dos modos possíveis de representação do feminino - realizamos uma análise crítica cultural da mídia ancorados, especialmente, em referenciais teórico-políticos caros aos estudos de gênero/feministas.

Convenção das Bruxas (1990), Abracadabra (1993), Da magia à sedução (1998) e Harry Potter e a Pedra Filosofal (2001), ao trazerem determinadas bruxas/mulheres em posição de protagonismo/co-protagonismo, explicitam, também, lugares possíveis ou interditados às mulheres como um todo. Ao tomarmos a mídia como um dispositivo pedagógico (FISCHER, 2002), que ensina ao passo que mostra, ao percebermos o cinema como uma tecnologia de gênero (LAURETIS, 1994) e, ainda, ao considerarmos que tais produções inscrevem-se, sob tal prisma, como dispositivos discursivos de feminilidades (MACHADO, 2018), é possível perceber que, para além da fantasia, tais narrativas dizem sobre o ser (e os modos de ser e de não ser) mulher.

Em Senhorita Eva Ernst, de Convenção das Bruxas (1993), tem-se uma mulher diabólica e que, atualizando um discurso eclesiástico de demonização do feminino, representa um mal que precisa ser exterminado. Para além do grotesco camuflado por máscara, peruca e acessórios, contudo, as falhas de caráter da Grande Rainha Bruxa também são explicitadas via performance fortemente erotizada da vilã encarnada por Anjelica Huston. A punição (morte) é, portanto, a única alternativa cabível.

Winifred, Mary e Sarah Sanderson, de Abracadabra (1993), recuperam, do mesmo modo, a vilania. A busca por crianças e a lógica canibal de Abracadabra, contudo, têm um propósito em particular: a busca pela juventude e a inclusão a partir de dado padrão estético (padrão esse, cabe reiterar, performado pelas outras mulheres - não bruxas, não malignas - 
que se fazem presentes no enredo). Também perversas - embora atrapalhadas e, por conseguinte, engraçadas - essas mulheres, dignas de riso, não possuem direito àquilo que buscam. E a forca, a fogueira e, por fim, a explosão, evidenciam isso.

Da magia à sedução (1998), a partir das bruxas/mulheres da família Owens, inscreve-se em um discurso romântico o qual propicia uma ressignificação do feminino (RUSSELL; ALEXANDER, 2019). Na narrativa então constituída, a sororidade aparece como lugar privilegiado para pensar a mulher e as relações que, a despeito das diferenças, podem ser sim construídas entre elas.

Harry Potter e a Pedra Filosofal, por fim, ao trazer a figura da menina/bruxa, o faz a partir de um lugar onde ela performa um padrão hegemônico de feminilidade. Em uma escola - que também possui gênero - Hermione, ao contrário dos colegas meninos, é dedicada, comprometida, responsável e contida, ensinando um modo esperado de ser mulher tanto no mundo mágico quanto no mundo trouxa.

Tal qual asseverado, ainda que este trabalho represente um primeiro movimento em direção a um fenômeno mais amplo (e que seguramente requer análises mais abrangentes e aprofundadas), desde já alguns elementos fornecem pistas valiosas.

Ainda que tenhamos percebido representações plurais em relação à bruxa/mulher, há que se considerar, por exemplo, a ausência de diversidade étnica ou mesmo de orientação sexual nas produções analisadas. Todas as bruxas/mulheres então estudadas são brancas e, a princípio, heterossexuais.

Para além dos poderes, foi possível constatar que, em especial naqueles filmes que se aproximavam de um discurso eclesiástico para compreender a bruxaria (CONVENÇÃO DAS BRUXAS, 1990; ABRACADABRA, 1993), as falhas de caráter das personagens estavam diretamente relacionadas a uma performance de gênero perturbadora: o exagero, manifesto via sensualidade exacerbada, a maquiagem carregada e a risada estridente, por exemplo, são índices recorrentes e que, em movimentos futuros, podem operar como marcadores importantes. Com esses filmes, viu-se que se ensinava, em especial, sobre como uma mulher não deve ser e como aqueles corpos estranhos (LOURO, 2008) precisavam ser contidos.

Harry Potter e a Pedra Filosofal, com Hermione, sugere o passo a passo de um padrão de comportamento esperado para as garotas e, nesse sentido, fala sobre como uma mulher deve ser (algo que, como já temos observado, acentua-se conforme a idade da personagem avança). Da magia à sedução (1998), filme que mais se alinha a uma crítica ao modelo de sociedade patriarcal dentre os aqui estudados, de modo didático e político, mostra sobre o 
poder que reside na irmandade feminina. Para a continuação desta e de outras pesquisas semelhantes, enfim, há portas que se abrem.

\section{Referências}

AUAD, Daniela. Educar meninas e meninos: relações de gênero na escola. São Paulo: Editora Contexto, 2006.

BEAUVOIR, Simone. 0 segundo sexo: a experiência vivida. São Paulo: Difusão Europeia do livro. 1967.

BECKER, Márcia Regina; BARBOSA, Carla Melissa. Sororidade em Marcela Lagarde y de los Ríos e Experiências de Vida e Formação em Marie-Christine Josso e algumas reflexões sobre o saber-fazer-pensar nas Ciências Humanas. Coisas do Gênero: Revista de Estudos Feministas em Teologia e Religião, São Leopoldo, v. 2, n. 2, p. 243-256, 2016.

BENNETT, Alanna. "Practical magic" is 20 years old and just as relevant as ever. BuzzFeed News, [s.l.], 16 out. 2018. Disponível em:

https://www.buzzfeednews.com/article/alannabennett/practical-magic-20-violencewomen-witches. Acesso em: 20 ago. 2020.

BIRD, Anne-Marie. Women behaving badly: Dahl's witches meet the women of the eighties. Children's Literature in Education, [s.l.], v. 29, n. 3, p. 119-129, 1998.

BRASIL registra um caso de feminicídio a cada 7 horas. Catraca Livre, São Paulo, 23 nov. 2020. Disponível em: https://catracalivre.com.br/cidadania/brasil-registra-um-caso-defeminicidio-a-cada-7-horas/. Acesso em: 29 maio 2021.

BUTLER, Judith. Problemas de gênero: feminismo e subversão da identidade. São Paulo: Editora Record, 2012.

COSTA, Isabelle Rodrigues de Mattos. João, Maria e a bruxa das narrativas infantis. In: CUNHA, Maria Zilda da; MICHELLI, Regina; SANTOS, Rita de Cássia Silva Dionísio. 0 mal na narrativa para crianças e jovens: olhares da liteatura e do ensino. Rio de Janeiro: Dialogarts, 2020. p. 21-33.

CHANEY, Jen. The magical tale of how 'Hocus Pocus' went from box-office flop to halloween favorite. Yahoo!Entertainment, [s.l.], 28 out. 2015. Disponível em:

https://www.yahoo.com/entertainment/the-magical-tale-of-how-hocus-pocus-went-from144105863.html?guccounter=1. Acesso em: 20 ago. 2020.

DAHL, Roald. As Bruxas. Alfragide: Leya, 2019.

FEDERICI, Silvia. Calibã e a bruxa: mulheres, corpos e acumulação primitiva. São Paulo: Elefante, 2017.

FISCHER, Rosa Maria Bueno. 0 dispositivo pedagógico da mídia: modos de se educar na (e pela) TV. In: Educação e Pesquisa, São Paulo, v.28, n.1, p. 151-162, jan./jun. 2002. 
HOFFMAN Alice. Practical Magic. Berkley: Penguin, 2003.

JANOTTI JUNIOR, Jeder. Cultura pop: entre o popular e a distinção. In: SÁ, Simone Pereira de; CARREIRO, Rodrigo; FERRARAZ, Rogerio. Cultura pop. Salvador: EDUFBA: 2015. p. 4556.

JENKINS, Henry. Invasores do texto: fãs e cultura participativa. Nova Iguaçu: Marsupial Editora, 2015.

KRAMER, Heinrich; SPRENGER, James. 0 Martelo das Feiticeiras. Rio de Janeiro: Rosa dos Tempos, 2002.

KELLNER, Douglas. A cultura da mídia. Bauru: EDUSC, 2001.

LAURETIS, Teresa de. A tecnologia do gênero. In: HOLANDA, Heloisa Buarque de (Org.).

Tendências e impasses: o feminismo como crítica da cultura. Rio de Janeiro: Rocco. 1994, p. 206-242.

LOPES, Marina; SILVA, Regiany. Igualdade de gênero nas carreiras demanda mudança em casa, na escola e na universidade. Porvir, São Paulo, 8 mar. 2018. Disponível em: https://porvir.org/igualdade-de-genero-nas-carreiras-demanda-mudanca-em-casa-naescola-e-na-universidade/. Acesso em: 20 ago. 2020.

LOURO, Guacira Lopes. Gênero, sexualidade e educação. Petrópolis: vozes, 1997.

LOURO, Guacira Lopes. Um corpo estranho. Belo Horizonte: Autêntica, 2008.

MACHADO, Felipe Viero Kolinski. Homens que se veem: masculinidades nas revistas Junior e Men's Health Portugal. Ouro Preto: Editora UFOP, 2018.

MACHADO, Felipe Viero Kolinski. Seja Jovem: sentidos sobre a velhice em cinquenta anos de Veja (1968-2017). Ouro Preto: Editora UFOP, 2020.

MACIEL, Luana Bernardes. A representação da mulher por meio da sororidade e rivalidade construídas na produção seriada Big Little Lies. 2019. Trabalho de Conclusão de Curso. (Graduação em Jornalismo) - Universidade Federal de Ouro Preto, Mariana, 2019.

MELO, João Batista. Lanterna mágica: infância e cinema infantil. Rio de Janeiro: Civilização Brasileira, 2011.

MOSELEY, Rachel. Glamorous witchcraft: gender and magic in teen film and television. Screen, Glasglow, v. 43, n. 4, p. 403-422, 2002.

MURARO, Rose Marie. Breve introdução histórica. In: KRAMER, Heinrich; SPRENGER, James. O Martelo das Feiticeiras. Rio de Janeiro: Rosa dos Tempos, 2002.

PORTELA, Ludmila Noeme Santos. Malleus Maleficarum: bruxaria e misoginia na Baixa Idade Média. Religare, João Pessoa, v.14, n.2, p. 252-281, 2017. 
POTTER makes. Potter makes movie chart history. CBBC, [s.l.], 19 fev. 2002. Disponível em: http://news.bbc.co.uk/cbbcnews/hi/tv_film/newsid_1828000/1828977.stm. Acesso em: 20 ago. 2020.

PRECIADO, Paul B. Manifesto Contrassexual. São Paulo: N-1 Edições, 2014.

RUSSELL, Jeffrey B.; ALEXANDER, Brooks. História da Bruxaria: Feiticeiras, hereges e pagãs. São Paulo: Aleph, 2019.

SÁ, Simone Pereira de; CARREIRO, Rodrigo; FERRARAZ, Rogerio. Cultura pop. Salvador: EDUFBA, 2015.

SAFFIOTI, Heleieth. Gênero, patriarcado, violência. 2. ed. São Paulo: Expressão Popular: Fundação Perseu Abramo, 2015.

SOARES, Thiago. Abordagens teóricas para estudos sobre cultura pop. Logos, Rio de Janeiro, v. 2, n. 24, 2014.

STEWART, Kathleen. Ordinary affects. Durham: Duke University Press Book. 2007

THE WITCHES. In: The Numbers: where data and the movie business meet. [Los Angeles, CA: Nash Information Services, 2021]. Disponível em: https://www.the-

numbers.com/movie/Witches-The\#tab=summary. Acesso em: 20 ago. 2020.

THE WITCHES. In: Rotten Tomatoes. [Beverly Hills, CA: Fandango, 2020] Disponível em: https://www.rottentomatoes.com/m/the_witches. Acesso em: 20 ago. 2020.

UN WOMEN. Families in a changing world. [USA], 2019. Disponível em: https://www.onumulheres.org.br/wp-content/uploads/2019/06/Progress-of-the-worldswomen-2019-2020-en.pdf. Acesso em: 20 ago. 2020.

WITTIG, Monique. El pensamiento heterosexual y otros ensayos. Barcelona: Egales, 2010.

WOLF, Naomi. 0 mito da beleza. Rio de Janeiro: Rocco, 1992.

WOODWARD, Kathryn. Identidade e diferença: uma introdução teórica e conceitual. In: SILVA, Tomas Tadeu da. Identidade e diferença: a perspectiva dos estudos culturais. Petrópolis: Vozes, 2000. p. 7-72

ZORDAN, Paola Basso Menna Barreto Gomes. Bruxas: figuras de poder. Revista Estudos Feministas, Florianópolis, v. 13, n. 2, p. 331-341, 2005.

\section{Filmografia}

CONVENÇÃO das bruxas. Nicolas Roeg. EUA: Warner Bros. 1990, 1DVD (91 min). Título original: The Witches.

ABRACADABRA. Kenny Ortega. EUA: Walt Disney Picture, 1993. 1 DVD (96 min). Título original: Hocus Pocus. 
DA MAGIA à Sedução. Griffin Dunne. EUA: Warner Bros. 1998.. 1 DVD (93 min). Título original: Practical Magic.

HARRY Potter e a Pedra Filosofal. Chris Columbus. EUA: Warner Bros, 2001. 1DVD (159 min). Título original: Harry Potter and the Philosopher's Stone.

\title{
Because not all witch is hump: senses about being a witch/being a woman in children's and adolescents films
}

\begin{abstract}
The aim of this work is to understand how certain films aimed at children and adolescents represent the figure of the witch / woman. For this, we undertake a critical cultural analysis of the media, based on references of gender studies / feminist studies. With The Witches, Hocus Pocus, Practical Magic and Harry Potter and the Philosopher's Stone we perceive multiple representations. Among the figure that incorporates evil, the figure that does not follow a certain performance and deserves to be punished, the figure that perceives the relevance of sorority and the figure that embodies the gender in a desirable way, we have, in addition to the fantastic plot, a political discussion about ways of being / not being a woman.
\end{abstract}

\section{Keywords}

Witch/Woman. Gender. Representation. Children and adolescents films. Cultural critical analysis of the media.

\section{Autores para correspondência}

Felipe Viero Kolinski Machado Mendonça

felipeviero@gmail.com

Jussara de Souza Lima da Silva

Jusouza.jf2@gmail.com

\section{Como citar}

MENDONÇA, Felipe Viero Kolinski Machado; SILVA, Jussara de Souza Lima da. Porque nem toda feiticeira é corcunda: sentidos sobre o ser bruxa/ser mulher em filmes infantis e infantojuvenis. Intexto, Porto Alegre, n. 52, e-106691, jan./dez. 2021. DOI: http://dx.doi.org/10.19132/1807-8583202152.106691 